My experiences with social media for scholarship research and networking were certainly positive. Social media allowed me to form dialogues with scholars and readers outside my own field of expertise and create a mutually beneficial exchange of knowledge. Having a presence in social media essentially meant I had a public platform that made my work accessible to a wider range of scholars - some I never would have come across in conferences simply because of disciplinary barriers.

Jaipreet Virdi-Dhesi

IHPST, University of Toronto, Canada

doi:10.1017/mdh.2014.65

\title{
Social Media Trends in Medical History
}

\section{My Own Private Ishkabibble}

The community of experts of which we are a part has contributed, ironically, to what looks a lot like the decline of expertise. In recent decades, post-modern relativism in the humanities has coincided with cultural trends ranging from left-wing identity politics to right-wing Fox News: thus, even experts derogate expertise as 'elitism' and persist in the mistaken view that everyone's opinion is as good as any other's. ${ }^{1}$ Social media are both cause and effect of this trend. Blogs blur the line separating expert from ignoramus. Many of us get our daily news not from the New York Times or Washington Post that once smacked our front doors, but from Facebook or Twitter, where links to Times and Post articles show up in our feeds, filtered by friends and followers and interspersed with photos of cats doing funny things. Cranks and cuckoos abound on the internet, of course, and what passes for discourse is often less like a stimulating dinner party than like a barroom fight. Such foolishness is antithetical to sober intellectual institutions such as peer review or the academic conference, is it not?

Yes and no. Historians of biomedicine will know of the International Society for the History, Philosophy, and Social Studies of Biology - known to initiates as 'Ishkabibble'. That unwieldy name actually understates its constituency, because a small but vocal contingent of actual biologists always attends as well. I have a love/hate relationship with Ish. Like the internet, it has its flame wars. A session gets hijacked by two scholars dominating the Q\&A with their personal argument. Scientists tell the historians, 'You're wrong; I was there'; the historians reply that that is precisely the problem. At one memorable Ishkabibble meeting, in Vienna, two philosophers got into a drunken brawl. But when it works, Ish can be brilliant: smart people with a broad range of training and experience, discussing and debating substantive issues of common interest. At its best, Ishkabibble is a meeting where everyone brings a unique perspective, speaks in a common language, and opens each others' minds.

My Twitter feed is like Ish on steroids. It is the International Society of Historians, Philosophers, Sociologists, Journalists, Scientists, Physicians, Genetic Counselors, Biotech Executives, Novelists, Motorcycle Mechanics, Tattoo Artists and, for some reason I still do not completely understand, the City of Los Gatos, CA. My following is modest

\footnotetext{
${ }^{1}$ Similar views have been expressed by trenchant curmudgeons for years and continue today. See, e.g., Paul Forman, 'In the Era of the Earmark: The Postmodern Pejoration of Meritocracy - and of Peer Review', Recent Science Newsletter, 2, 3 (2001), 1: 10-12; Tom Nichols, 'The Death of Expertise', posted 17 Jan. 2014 (http://thefederalist.com/2014/01/17/the-death-of-expertise/).
} 
by Twitter standards - under 1000. But that is more than the attendance at the 2013 Ishkabibble meeting or the American Association for the History of Medicine. A few strategic retweets and my blog posts, queries and observations can easily reach tens of thousands. Like everyone else, I get my share of cranks and derailers, but when it works, it is like my own private Ishkabibble: a motley society of my own creation, informing me about the latest happenings in biomedicine and bringing a wide degree of expertise to bear on questions I care about.

For example: I am assembling a cross-disciplinary undergraduate course on writing about science and medicine. It is going to be part history of popular knowledge, part literary criticism seminar, part writing workshop. I asked the 'hive mind' for suggestions of their favourite writers and writings. I got a huge response, on both Twitter and Facebook, with suggestions from many quarters: journalists, scientists, novelists and poets, and a juggler who is running for mayor. In a day and a half, I built a long list of books and essays, which I am currently reading and considering for my syllabus. Some of the most interesting suggestions came from non-academics.

In other instances, offhand remarks and silly wordplay I have instigated on Twitter have escalated into long-form discussions with high-profile science writers from the likes of Wired, Scientific American, Discover and yes, the New York Times. These people have many thousands of followers, and their chatting with me helps my blog posts reach the biomedical, biotech, pharmaceutical and genetic-counselling communities (thus helping diversify my private society). For my part, I try to contribute serious history to public discussions on the role of science and medicine in society.

Such discussions do lack some of the geeky pleasures of scholarly debate and analysis a form of discourse I would not give up for a million Twitter followers. But writing for nonspecialists ought not to be seen as necessarily dumbing down one's work; breadth can be as sophisticated as depth. If you create your own private Ishkabibble with some care, nonspecialists in your area will be specialists in another. The result can be a mutual exchange of expertise, rather than a unidirectional transfer of knowledge. 'Interdisciplinarity' is a hackneyed buzzword around the university, often either deployed as a vague ideal with no substantive goal or construed so narrowly that the exchange of expertise is tightly constrained. Social media can slam home all the pleasures and dangers of true crosspollination. The history of medicine can both instruct and learn from journalism, the fine arts, social activism or carpentry.

The greatest problem with Twitter and social media is not the cliché that it is too frivolous for serious discourse. Rather, it is that too mисh interesting discussion and sharing of work takes place in those forums. Social media can become a full-time occupation - one with little-to-no direct compensation in the conventional academic currency of credit. Ironically, students are both the academics most likely to use social media and those who most need publication in traditional journals. The upheaval of peer review today is beyond my scope here, but for now, at least, young scholars face a true dilemma. To blog or not to blog, that is the question.

Further, the traffic is increasing between the wild west of social media and the staid, genteel 'East Coast' of the professional societies. Most of the societies in the study of science, technology and medicine are currently wrestling with how to relate to social media. They are holding workshops and round tables (I've participated in four in the last year), they are debating society policy on live-tweeting conference papers, and the tweeting and blogging grows rapidly for each conference. Again, this democratisation has pleasures and dangers. Twitter provides society members unable to attend, as well as 
a few interested laypeople, a simulacrum of the discussion - like a free low-resolution file download - and even lets them chime in with comments and questions. Concurrent sessions can cross-pollinate, as conferees tweet back and forth between rooms. Perhaps scholars will use less post-modern jargon if we know others are listening. Perhaps we will win new recruits to the field or sell a few more books. But there are legitimate concerns as well. Scholars might become guarded, feeling less free to discuss preliminary ideas, for fear of getting scooped or taken out of context. And the distraction caused by all those glowing devices (to their users and to those around them) can change the mood of a session, taking it from reflective and focused to an ADD-like state of hyper-arousal and flickering attention. A cogent argument can be made for accepting the merits of both the raucous world of social media and the calm introspection of private, elite academic discourse, but keeping them separate.

My response to that argument is this. First, the reflective idyll of academia is romantic and sentimental. Remember the brawl at the Vienna Ishkabibble. Academia is less like the nineteenth-century German university and more like Facebook than we like to admit; it is growing more social and distracted every year, and not all of that change has to do with social media. Sometimes I positively ache for a week - a day! - of calm reading and reflection, but the politics and business of the twenty-first century university make such times increasingly rare. We're not in Göttingen anymore, Toto. And so, second, resistance is futile. Opposition to social media as part of the academic life is diminishing as the professional escalator drops off senior scholars brought up on dial-up modems and picks up grad students and postdocs weaned on texting, video games, and Instagram. Standing a little more than halfway up to the Emeritus Mezzanine, I'm ambivalent about this change in scholarly practice, but I realize that my reservations matter not one curmudgeonly whit unless I know what I'm talking about. Expertise still does matter, and Luddites always lose. Finally, then, it is both more interesting and better for your blood pressure to understand the changes social media are wreaking on the life of the mind, whether you dive in with your clothes on, dabble a little, or just sit onshore and watch the waves roll in.

Nathaniel Comfort

Johns Hopkins University, USA 